\title{
Self-service Technology and Online Financial Service Choice
}

\author{
Xin Ding \\ Department of Information and Logistics Technology, \\ University of Houston, Houston, Texas, USA \\ Rohit Verma \\ Service Operations Management, School of Hotel Administration, \\ Cornell University, Ithaca, New York, USA, and \\ Zafar lqbal \\ Department of Marketing, DePaul University, Chicago, Illinois, USA
}

\begin{abstract}
Purpose - The application of self-service technology in transaction-based e-service (e.g. online financial services) creates a challenge for firms: what combination of features should they offer to satisfy needs from different customer segments? This paper seeks to address the above question by highlighting similarities and differences of consumer preferences among self-service, hybrid service and professional service segments for online financial services.
\end{abstract}

Design/methodology/approach - This study employs a web-based discrete choice experiment, in which 1,319 consumers were offered different account alternatives, which include features for self-service and professional assistance, price per transaction, and promotion offers.

Findings - The results demonstrate that overall, consumer preferences for features of online financial services differ across segments. Moreover, with the variation in the strength of self-reliance, interesting trends regarding the relative importance of features are observed. With the given customer segments, this study also identifies several demographic features with significant effects on the choice of service alternatives through a multinomial logistic model.

Originality/value - The authors believe that these results have both managerial and research implications for design and operations strategy formulation for online financial services.

Keywords Self-service, Financial services, Electronic commerce, Customer requirements, Customer satisfaction

Paper type Research paper 


\section{Introduction}

The evolution of self-service technology (SST) has tremendously changed the way customers interact with firms to create service outcomes. Broadly speaking, previous interpersonal care in the service sector has been gradually substituted by the do-it-yourself option. The prevalence of online banking, shopping, brokerage and package tracking demonstrates that technology-based self-service continues to be a critical component for customer-firm interactions.

The self-service option not only gives customers more control over the service process but also reduces the workload of service vendors. The benefits associated with self-service have been well-documented in prior research. For example, Bendapudi and Leone (2003) identified that the self-service customer takes more responsibilities than is warranted and tends to place less blame on the service vendor in case of a service failure. Kelley et al. (1990) also stated that involving customer participation will eventually enhance service quality and customer satisfaction.

As suggested by Globerson and Maggard (1991), self-services are differentiated from professional services as those activities performed by customers without the presence of an employee of the organization. In other words, self-service customers perform service-related activities that otherwise would have been performed by the employee. Identified by previous research in marketing, self-service and personal-service customers have different expectations from a service. For instance, customers preferring self-service rate perceived control, time and cost saving as critical factors involved in the service process. In addition, self-service customers in offline settings prefer behavioral control and tend to avoid personal contact, thinking they can serve themselves more efficiently than relying on others (Bateson, 1985; Dabholkar, 1996; Meuter and Bitner, 1998; Howard and Worboys, 2003).

Although previous research has identified a set of motivations for customers choosing offline self-service, it is unclear whether the above generalization is also applicable to online services. Furthermore, previous research on SST has focused on largely low involvement services such as those in the retail space (banking, airline-check-in, grocery self-checkout, etc.). Many of these services, while involving SST, placed minimal cognitive demands on the part of customers. Many of these SSTs, while initially difficult to use, tend to evolve into routine behavior over time (e.g. withdrawing money from an ATM machine). Very little research has explored the role of SST in a high involvement service such as that of financial investments. Some prior studies only partially support the applicability of the above stated generalizations in online financial services. Sarel and Marmorstein (2003) found that customers choose ATM and telephone banking in order to save time. Boyes and Stone (2003) suggested in their study that customers intend to conduct research prior to making their purchase rather than to take the sellers' claims at face value. As shown in previous studies, the degree of customer involvement in the co-production service process can affect service delivery, output quality, and customer satisfaction (Cook et al., 1999; Bendapudi and Leone, 2003). Therefore, it is important to study 
how the degree of customer involvement in the co-production process affects the incentives for adopting self-service, which helps managers and web site designers alike to customize the service options to further improve customer experience, and maximize customer satisfaction and loyalty.

Compared with retail banking, package tracking, and grocery shopping, financial services such as stock trading also have credence qualities (Brush and Artz, 1999). In other words, without professional knowledge in financial investment, it is difficult to evaluate the financial services even after some trail has occurred (Lovelock, 2001; Ostrom and lacobucci, 1995). As suggested by Holmlund (2001), the complex nature of the information exchanges in credence service is very important to customer's satisfaction and trust perception. In addition, professional knowledge is of critical importance and serves as a competitive advantage for the credence service (Brush and Artz, 1999). Based on above arguments, we think the common drivers of self-service in the context of low customer involvement or "easy to evaluate" settings may not be applicable in the context of e-financial service. Since, few studies have explicitly investigated the motivations for consumers choosing online self-service versus offline professional service when customer involvement is extremely high and the service requires a high level presence of credence characteristics, we think our study makes a significant contribution to the field of service industry management by filling the gap.

In this study, we investigated what drives customers to choose self-services versus professional service within the context of a high involvement service, viz online financial service. Those drivers could be modified and applied to some other online services, such as online banking, online shopping, as well as online education, etc.

Following the logic of Globerson and Maggard (1991), we first classified customers into self-service $(n=690)$, professional service $(n=132)$ and hybrid service $(n=487)$ segments. The self-service segment consists of subjects who like to manage their investments by themselves with no assistance and by using online sources. We define the hybrid segment as the people who choose to manage their investments by themselves and to consult friends or family members. The segment of professional service includes those subjects who like to work with a professional financial advisor/broker.

Given the customer segments, we applied discrete choice analysis (DCA) to study the heterogeneity in preferences across segments. If the given customer segments indeed vary in their service desires, it should be possible to customize online financial service attributes for different customer segments, which would improve both effectiveness and efficiency of targeting the appropriate customer segment. If, in contrast, customers view online financial services similarly across segments, and if that perspective consistently affects outcomes such as customer satisfactions across segments, vendors should be able to create online services that appear identical across customer segments, enabling them to leverage economies of scale (Mentzer et al., 2001). 
To address the issues mentioned above, we aim to achieve the following research objectives:

R01. Study which attributes drive customers to choose self-service versus professional service in the online-financial industry domain.

RO2. Study whether individual choice of service channels are affected by relevant demographic features of age, gender, Internet access history, as well as education levels and occupation.

We believe that this paper makes two significant contributions to the SST literature. First, it extends the literature to incorporate the online realm as a means of delivering self-service capability. In doing so, the theories developed around explaining self-service adoption behavior are tested and possibly modified to incorporate the online realm. Second, we further extend the literature to explain self-service in the context of high involvement credence services. This is a significant extension to the literature and will help other researchers and practitioners adapt current frameworks to explain and understand a wider range of services than previously possible.

To investigate the stated research objectives, we first identified three customer segments for self-service, professional service, and hybrid service. Then, we collected empirical data using DCA to determine the relative values of various attributes. To achieve the second objective, we applied a logistic regression model to investigate the relationship between customer demographic features and their preference towards service alternatives. By examining the model fit and likelihood ratio $\times 2$ statistics, we identify several features that significantly correlate with customer choice of service alternatives.

We believe that pursuing the above two objectives will add to current research in the area of self-service in the online realm, more specifically self-service in the high-involvement services realm and will also assist firms in effectively designing customized service offerings. The rest of the paper is organized as follows: we first review relevant literature on self-service and propose a theoretical framework; next, we describe our research design and methodology; then we analyze the outcomes of the discrete choice model and the multinomial logistic model; we conclude the paper with managerial insights and future research direction.

\section{Theoretical Framework}

With the evolution of SST, many researchers have acknowledged a need for greater understanding of the interactions between customers and firms in technology-based selfservices (Parasuraman, 1996; Dabholkar, 1996; Bitner et al., 1994; Meuter and Bitner, 1998). For example, Dabholkar and Bagozzi (2002) investigated the moderating effects of consumer traits and situational factors on the relationships between customers and firms using a core attitudinal model for technology-based self-service. Meuter et al. (2000) identified several factors that appear to influence dis/satisfaction with technology-based service encounters, 
providing some insights for the firms that currently provide or are planning to offer self-service as an alternative method of service delivery. Lee and Allaway (2002) studied whether the provision of more personal control to consumers can reduce their perceived risk, enhance the perceived value of self-service, and induce greater adoption intention associated with the innovation.

An overview of previous literature in SST suggests that users prefer self-service to professional service for several reasons, which include time saving (Bateson, 1985; Meuter et al., 2000; Howard and Worboys, 2003), cost saving (Dabholkar, 1996; Meuter et al., 2000), personal behavioral control (Bateson, 1985; Dabholkar, 1996; Meuter et al., 2000), ease of use (Meuter et al., 2000; Zeithaml et al., 2000; Yang and Jun, 2002), and to avoid service personnel and dependence (Bateson, 1985). The following section describes the three major latent constructs of cost saving, time saving, and behavioral control adopted in this study (Figure 1).

\section{Cost Saving}

Perceived cost saving is viewed as the extent to which a person believes that using a particular system will save his or her money expended on the service process. Meuter et al. (2000) identified the factor of "saved money" and other financial benefits as one of the subcategories driving customers to choose self-service. Howard and Worboys (2003) found that price and cost saving as one of the big advantages favoring self-service. Globerson and Maggard (1991) indicated the more effort the customer is required to invest in self-service, the lower the price the customer is typically willing to pay for that service. A few examples demonstrate the case: dining in a full-service restaurant as compared to a self-service one, and sending regular, unsorted mail compared to bulk mail sorted by zip code (bulk mail in the USA costs approximately one third of regular mail). In this study, we operationalize cost saving as the price level, which is manipulated by varying price per transaction. Since, promotions are generally associated with monetary savings, we also include promotions as one factor of cost saving.

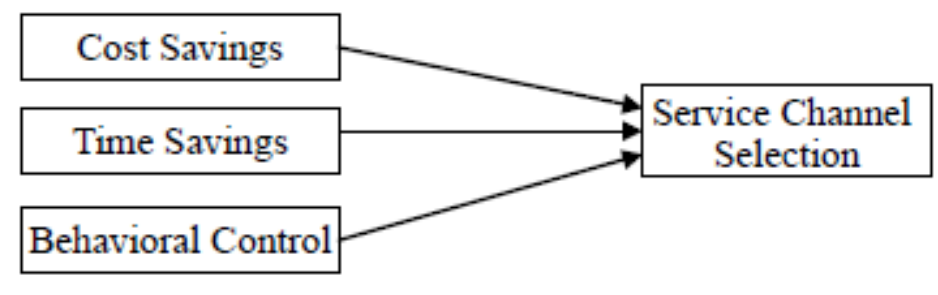

Figure 1. Theoretical framework

\section{Time Saving}

Perceived time saving is viewed as the extent to which a person believes that using a particular system would save his or her time expended on the service process. As technologybased self-service has been described as allowing the actual service to be performed more quickly or efficiently than does the traditional interpersonal alternative, time saving is rated as 
the most important factor for choosing self-service among all dimensions associated with customers' attitudes towards technology-based self-service. The theoretical importance of perceived time saving as a determinant of user perceived performance of electronic self-service and user behavior is supported by several diverse lines of research.

Bateson (1985) used discriminant analysis to study consumers' choice process when faced with the choice between a do-it-yourself option and a more traditional service delivery system and found respondents rated "perceived time taken" as the most important dimension. Meuter et al. (2000) categorized the results from a critical incident study conducted through a web-based survey and pointed out "saved time" as the largest of the six subcategories in favor of self-service. In addition, time saving is perceived as the biggest advantage of self-service by 50 percent of the population (Howard and Worboys, 2003). Berry et al. (2002) defined service convenience as consumers' time and effort perceptions related to buying or using a service. They proposed that the service convenience will lead to superiority of service quality and customers' satisfaction levels.

In this study, for online financial services, time saving is operationalized as the ability to apply online and be trading in minutes, availability of streaming quotes and streaming news, as well as availability of real-time profit and loss portfolio evaluation. The option of access to local branches is also included in this category, because it reflects customers' reluctance towards waiting for service at local branches.

\section{Behavioral Control}

Defined as "customers' ability to successfully perform the service tasks without service personnel contact," behavioral control has also been identified to impact perceived performance of technology-based self-service. Langeard et al. (1981) and Bateson (1985) surveyed self-service consumers and found that they preferred options that favored efficiency and increased control. Other researchers (Dabholkar, 1996) proposed that consumers who enjoy self-service also perceive greater control and higher service quality. Bateson (1985) examined the attractiveness of self-service options when the usual monetary or time-saving incentives are controlled and found that a significant group of people choose to use a selfservice option even without monetary or time-saving benefits, which could be partially explained by the dimension of perceived control. Bateson further suggested that many selfservice options could be built around the consumers' perception of control over the transaction. Meuter et al. (2000) state that a number of the benefits of self-service encounters can be related to aspects of personal control. In their study on the distribution of critical incidents, personal control amounts up to 32 percent of total incidents.

Based on the theory of planned behavior, Taylor and Todd (1995) decomposed control belief into two components. The first component is self-efficacy, which is an individual's selfconfidence in his/her ability to perform a behavior. Accordingly, we operationalize self-efficacy in online financial services as the access to overall-fee based, professionally managed accounts 
with a pre-determined investing strategy, where customers have very little control over the process and therefore cannot perform the service by themselves. The second component of decomposed control belief is "facilitating conditions," which reflects the availability of external resources needed to engage in a behavior, such as technology compatibility. Respectively, we refer to facilitating conditions in online financial service as the access to portfolio asset allocation modeling with stock ideas, the access to proprietary research at no additional cost, and access to IPOs for all account holders in this category, because the above three functions facilitate customers to successfully perform the online financial service.

\section{Research Design}

Based on a question that asked customers to self-select themselves into categories of service used when using online financial services, we created a classification scheme. Following the definition of self-service by Globerson and Maggard (1991), we redefine self-service as the service performed by customers themselves without the assistance from external personnel. Following the same logic, we define professional service as the service solely performed by the service professionals; we also define hybrid service as the service carried out by customers themselves as well as with the input from external personnel.

Table I demonstrates the classification segments adopted in this study: For people that selected "I like to manage my investments myself with no assistance" and "I like to manage my investments myself but check or augment my plans using other resources including online service," we classified them as pure self-service users. For customers who selected "I like to manage my investment myself and seek help from either friends or professionals," we classified them as hybrid service users. For those who selected "I like working with a professional financial advisor/broker," we classified them as professional service users, which means they are relying on personal contact with professionals in determining their investments.

\begin{tabular}{|c|c|c|c|c|}
\hline 1st category & 2nd category & Service type & Num & $\begin{array}{l}\text { Cumulative } \\
\text { percent }\end{array}$ \\
\hline $\begin{array}{l}\text { I like to manage my investments } \\
\text { myself }\end{array}$ & With no assistance & Self-service & 151 & 11.4 \\
\hline & $\begin{array}{l}\text { Check or augment my plans } \\
\text { using other resources } \\
\text { Check or augment my plans } \\
\text { with friends or family }\end{array}$ & $\begin{array}{l}\text { Hybrid } \\
\text { service }\end{array}$ & 539 & $\begin{array}{l}52.3 \\
62.3\end{array}$ \\
\hline $\begin{array}{l}\text { I like working with in-person } \\
\text { professional financial advisor }\end{array}$ & $\begin{array}{l}\text { Want to understand everything } \\
\text { he/she is doing } \\
\text { Do not want to get bogged } \\
\text { down in the details myself }\end{array}$ & $\begin{array}{l}\text { Professional } \\
\text { service }\end{array}$ & $\begin{array}{l}214 \\
283\end{array}$ & 78.5 \\
\hline
\end{tabular}

Table 1. Categories and frequencies 


\section{Online Financial Service Attributes}

Given our conceptual variables of interest, namely, professional service features of access to brick-and-mortar facilities, self-service features of access to the online service via the online medium, price per transaction, and behavioral controls, we chose our attributes on the basis of their judged fit with our conceptual variables. Specifically, we collected qualitative data from high-level executives in the financial services industry and requested them to suggest online service attributes and levels that reflected our conceptual variables. The final panel of attributes was selected by modifying attributes from the executives' suggestions and reviewing existing online and offline services in the chosen industry. We then showed the new list of attributes to two different executives and also to the initial four executives, and on the basis of their classification, we refined our list of attributes and levels. Finally, we showed our list of attributes to two business school professors, both of whom were blind to the purpose of the study, and asked them to verify our classification. The interrater agreement was very close and subsequent discussions resolved any differences.

Table II lists our selected attributes, and levels. In all, we manipulated ten online financial-service attributes at different levels. The independent variables (attributes) can be classified in the following latent categories: cost saving, time saving, and behavioral control.

\begin{tabular}{lll}
\hline Constructs & Attributes & Level \\
\hline Cost saving & Price/transaction in \$ amounts (PRICE) & Level 1: \$10 \\
& & Level 2: \$15 \\
& Level 3: \$20 \\
& Special offer for the new customers (PROMOTION) & Level 4: \$25 \\
& & Level 1: No \\
Time saving & Access to local branches (BRANCH) & Level 2: Yes \\
& & Level 1: No \\
& Ability to apply on-line and be trading in minutes (APP ONLINE) & Level 2: Yes \\
& & Level 1: No \\
& Availability of streaming quotes and streaming news (REALTIME & Level 1: No \\
& INFO) & Level 2: Yes \\
& Availability of real-time profit and loss portfolio evaluation & Level 1: No \\
& (REALTIME EVAL) & Level 2: Yes \\
Access to overall-fee based, professionally managed accounts with & Level 1: No \\
& a pre-determined investing strategy (PROFMGT) & Level 2: Yes \\
& Access to portfolio asset allocation modeling with stock ideas & Level 1: No \\
& (ASSET ALLO) & Level 2: Yes \\
Access to proprietary research at no additional cost (R\&A) & Level 1: No \\
& & Level 2: Yes \\
& Access to IPOs for all account holders (IPOS) & Level 1: No \\
& Level 2: Yes \\
& &
\end{tabular}

Table II. List of attributes, and levels 
Cost saving was manipulated by varying price per transaction at four levels and manipulating marketing promotions at two levels of 25 free transactions in a given time period or $\$ 100$ credit to open an account. Time saving features included four attributes:

(1) access to local branches;

(2) ability to apply online and be trading in minutes;

(3) availability of streaming quotes and streaming news; and

(4) availability of real-time profit and loss portfolio evaluation.

Behavioral control features included four attributes:

(1) access to overall-fee based, professionally managed accounts with a pre-determined investing strategy;

(2) access to portfolio asset allocation modeling with stock ideas;

(3) access to proprietary research at no additional cost; and

(4) access to IPOs for all account holders.

Each of the above attributes, except price per transaction and special offer were varied in a binary format, that is, either as being available or not.

\section{Experimental Design}

We used a fractional factorial design that simultaneously created both the onlinefinancial service profiles as well as the choice sets into which to place them. We created 16 orthogonal fractional factorial profiles that allowed us to reliably estimate all the main effects of the attributes included. In order to generate the discrete choice sets, we used a "foldover" design approach suggested by Louviere (1988). A foldover design contains the opposite levels of every attribute for a given profile and therefore presents two completely orthogonal profiles to respondents in each choice set. This experimental design procedure has been used and recommended by other DCA studies focused on service applications (Verma et al., 2001).

We pre-tested the online-financial services choice task with 50 randomly selected customers to ensure ease and comprehension of the task, as well as to ensure reliable data collection methods. Average task completion time was approximately 10 minutes and respondents did not indicate difficulty in task comprehension. A sample choice set is presented in Table III. In addition to the online financial service choice tasks, the survey instrument included general demographic questions (e.g. age, gender, education, and marital status). In addition, we also asked the customers to rate their individual involvement in the purchasing decision on a six-point scale. The purpose of including this question was to only select the respondents with a high degree of involvement with the online financial service. This further supports the contribution of our research in extending the literature on SST to services with a high level of customer involvement. Only those respondents that indicated a high degree of involvement with the purchase decision, i.e. answered 4 or higher on a six-point scale, were included in our analysis. By including only involved customers in our study, we simulated a 
reasonable decision made by firms to initially target involved and motivated customers when introducing a new online-service.

\begin{tabular}{|c|c|c|}
\hline Attribute (market drivers) & Service A & Service B \\
\hline Price per transaction (presented in actual $\$$ amount to respondents) & $\$ 25$ & $\$ 15$ \\
\hline Availability of in-depth research and analysis at no additional cost & No & Yes \\
\hline $\begin{array}{l}\text { Option of account management by a professional staff for additional } \\
\text { fee }\end{array}$ & Yes & No \\
\hline Access to unique new products earlier than the open market & Yes & No \\
\hline Availability of real-time product information anytime, anywhere & No & Yes \\
\hline Availability of real-time customized account status & No & Yes \\
\hline Access to advanced analysis tools for better decision making & No & Yes \\
\hline Access to local branches & Yes & No \\
\hline Ability to apply and start using the account online within minutes & No & Yes \\
\hline Special offer for new customers & $\$ 100$ credit & $\begin{array}{l}25 \text { Free } \\
\text { Transactions }\end{array}$ \\
\hline I will chose to use this e-financial service $\rightarrow$ & $\begin{array}{l}\text { Service A _ } \\
\text { Neither _ }\end{array}$ & Service B_ \\
\hline
\end{tabular}

Table III. A sample e-financial service choice set

Sampling and data collection

The respondents were active consumers in the financial service industry and were part of a demographically balanced panel purchased from a large US-based, nationally reputed marketing research firm. Consumer panels are an appropriate sampling frame and have a rich history of business applications (Lohse et al., 2000). The study was administered to 10,000 consumers in the purchased panel with a non-response rate below 2 percent. Thus, gross nonresponse bias is not a factor in our study. As discussed early, we screened respondents on the basis of their response to a purchase involvement question. After screening for involvement, our sample size was 1,319 , with a qualified response rate of 13.2 percent. We divided the 1,319 respondents into groups of self-service $(n=690)$, hybrid service $(n=132)$, and professional service ( $n=487$ ) based on self-reported modality of online financial service usage. As demonstrated in Table IV, self-service segment dominates the whole sample population (52.31 percent). Hybrid service segment accounts for 10.01 percent of the total population, and 36.78 percent of the population preferred to use professional service.

During the data collection phase, each respondent received an e-mail from the research team with an invitation to join the research project. In addition to reimbursement from the marketing research firm for panel participation, each respondent's name was entered in a raffle for winning attractive prizes. After logging into a secure web site, each respondent then read a common core concept of the online service that held constant various non-experimental features across all choice sets. The features that were held constant included web site reliability, on-site support, privacy, security, breadth of product assortment, information 
quality, and web site usability. After reading the core concept, each respondent was asked to respond to 16 experimentally generated online financial service choice sets. Each choice set contained two versions of the online financial service (Table III). The respondents were asked to choose one of the two presented online financial service concepts or indicate that they refused to choose either. Half the respondents made choices in one order that was then reversed for the other half of the respondents. The order made no statistical difference to the results and will not be discussed further. Similar to the pretest, average task completion time was approximately 10 minutes.

\begin{tabular}{|c|c|c|c|c|}
\hline Characteristics & $\begin{array}{l}\text { Self-service } \\
\quad(n=690) \\
\text { (percentage) }\end{array}$ & $\begin{array}{l}\text { Hybrid service } \\
(n=132) \\
\text { (percentage) }\end{array}$ & $\begin{array}{c}\text { Professional service } \\
(n=497) \\
\text { (percentage) }\end{array}$ & $\begin{array}{c}\text { Total sample } \\
(n=1,319) \\
\text { (percentage) }\end{array}$ \\
\hline \multicolumn{5}{|l|}{ Age } \\
\hline Under 25 & 3.91 & 7.58 & 3.02 & 3.94 \\
\hline $25-34$ & 23.91 & 34.85 & 14.08 & 21.30 \\
\hline $35-44$ & 28.12 & 29.55 & 25.75 & 27.37 \\
\hline $45-54$ & 28.84 & 17.42 & 31.19 & 28.58 \\
\hline \multicolumn{4}{|l|}{ Gender } & 18.80 \\
\hline Male & 67.83 & 51.52 & 54.12 & 61.03 \\
\hline Female & 32.17 & 48.48 & 45.88 & 38.97 \\
\hline \multicolumn{5}{|l|}{ Education } \\
\hline Graduate + & 40.14 & 41.67 & 41.05 & 40.64 \\
\hline College + & 42.90 & 38.64 & 34.81 & 39.42 \\
\hline Some college & 14.93 & 17.42 & 20.32 & 17.21 \\
\hline High school + & 1.45 & 0.76 & 3.42 & 2.12 \\
\hline Less than high school & 0.58 & 1.52 & 0.40 & 0.61 \\
\hline \multicolumn{5}{|c|}{ History of web usage (years) } \\
\hline$<1$ & 1.88 & 3.03 & 2.41 & 2.20 \\
\hline $1-3$ & 15.36 & 21.21 & 22.74 & 18.73 \\
\hline $3-5$ & 22.03 & 25.00 & 30.78 & 25.63 \\
\hline 5 & 60.58 & 50.76 & 43.86 & 53.30 \\
\hline
\end{tabular}

Table IV. Sample characteristics - number of people who choose different approaches

\section{Analysis and Results}

\section{Financial services customer choice models}

As mentioned earlier, we use DCA to investigate how customers trade off time saving, cost saving, as well as behavioral control features in online financial service settings (Iqbal et al., 2003). DCA has been used to model choice processes of decision makers in a variety of academic disciplines, including marketing, operations management, hospitality, and natural resource economics (Louviere and Timmermans, 1990; Verma et al., 2001). Statistical models such as multinomial logit models developed from a DCA study link service attributes to 
consumer preferences, and can be used to predict market share and profit for any service offering in a competitive environment (Danaher, 1997).

Past studies have shown that in general, the market share predictions generated from the statistical model (e.g. multinomial logit) based on DCA are extremely accurate (Green and Krieger, 1996; Louviere and Timmermans, 1990). Therefore, DCA is useful for practicing managers and is used in this study to explore the consumer preferences for online financial services.

The first model demonstrates the preferences of self-service and professional service segments. As shown in Figure 2, consumers for both self-service and professional service are price sensitive and therefore prefer cost saving. Both segments place most value on the $\$ 10$ per trade option (P1(10)) and value least the \$25 per trade option (P4(25)). In addition, the selfservice segment is more price sensitive as the coefficient ratios between price and other independent variables for self-service segment are higher than the ratios for the professional service segment. Since, both self-service and professional service segments put most utilities on price (Figure 2 and Table V), it is relatively difficult to tell the difference between other factors

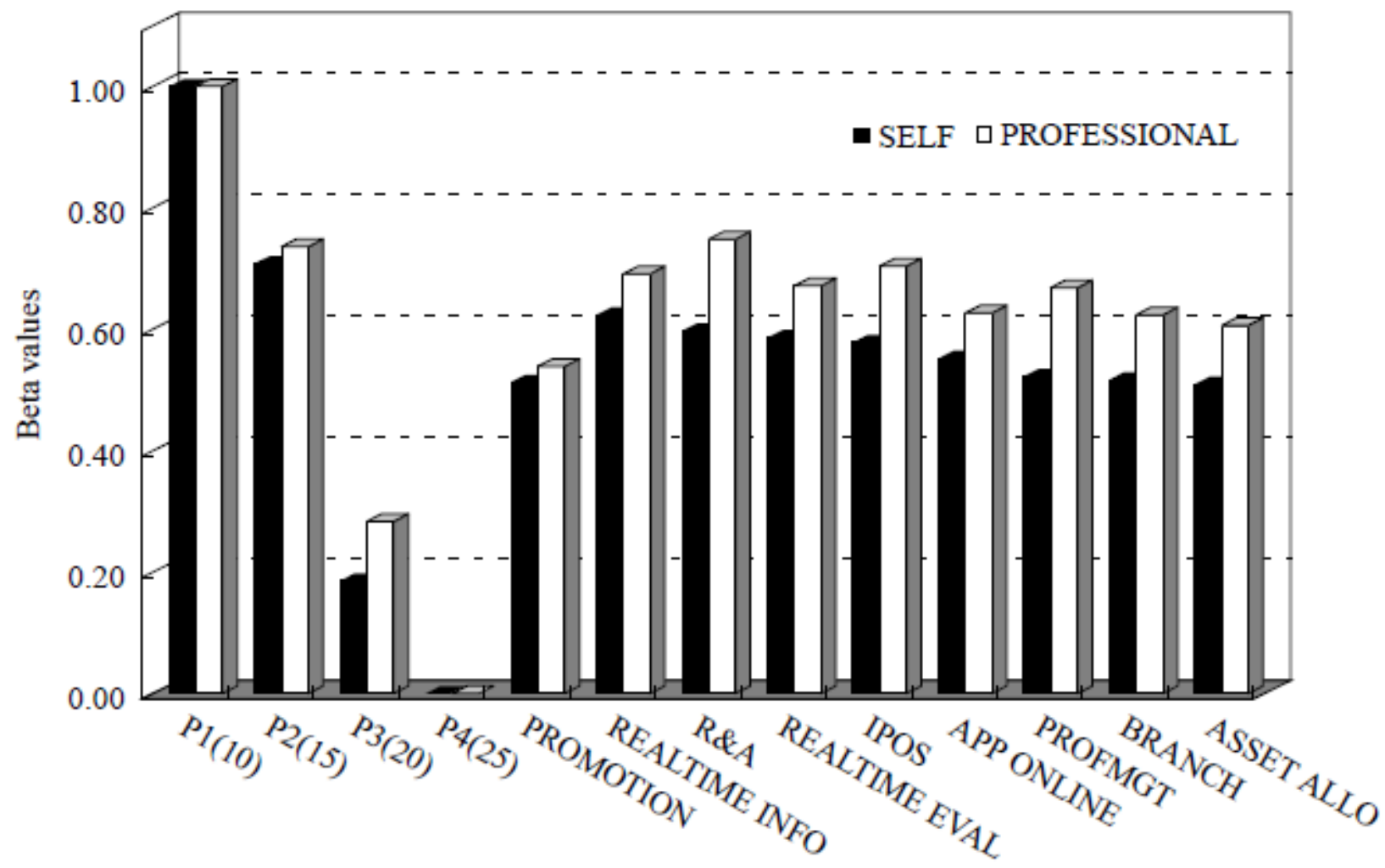

Figure 2. Comparison of two categories with price

across segments. To mediate this problem, we re-calculate and plot the coefficients' chart without considering the price per trade option (Figure 3). Some other patterns for both segments are also noted and are described in the following section. 
4.1.1 Self-service consumers. As discussed earlier, service marketing and service operations theories state that self-service users rate time saving and cost saving, personal control, as well as avoidance of personnel contact as the most significant factors for adopting self-service approach. The test results support the application of above generalization in online financial services. For time saving purpose, self-service consumers value the availability of real time information (REALTIME INFO), real time evaluation (REALTIME EVAL), and use the account online within minutes (APP ONLINE) higher than local branch (BRANCH) (REALTIME INFO =1, REALTIME EVAL $=0.6702$, APP ONLINE $=0.3727$, BRANCH $=0.0632$ ).

For behavioral control purpose, self-service consumers also value the availability of indepth research and analysis at no additional cost (R\&A) and access to IPOs (IPOS) more than fee-based professional managed accounts (PROFMGT) and asset allocation modeling with stock ideas (ASSET ALLO) (R\&A =0.76827, IPOS =0.6015, PROFMGT $=0.1124$, ASSET ALLO =0). The comparison supports that self-service consumers tend to have more control over their investments than to rely on either professional advisors or asset allocation models.

In summary, self-service consumers rate the availability of real time information and evaluation (REALTIME INFO and REALTIME EVAL), availability of in-depth research and analysis at no additional cost (R\&A), access to IPOs (IPOS), as well as use the account online within minutes (APP ONLINE) more important than other factors on the availability of the fee-based professional managed accounts (PROFMGT), asset allocation modeling with stock ideas (ASSET ALLO), local branch (BRANCH), and special offer (PROMOTION).

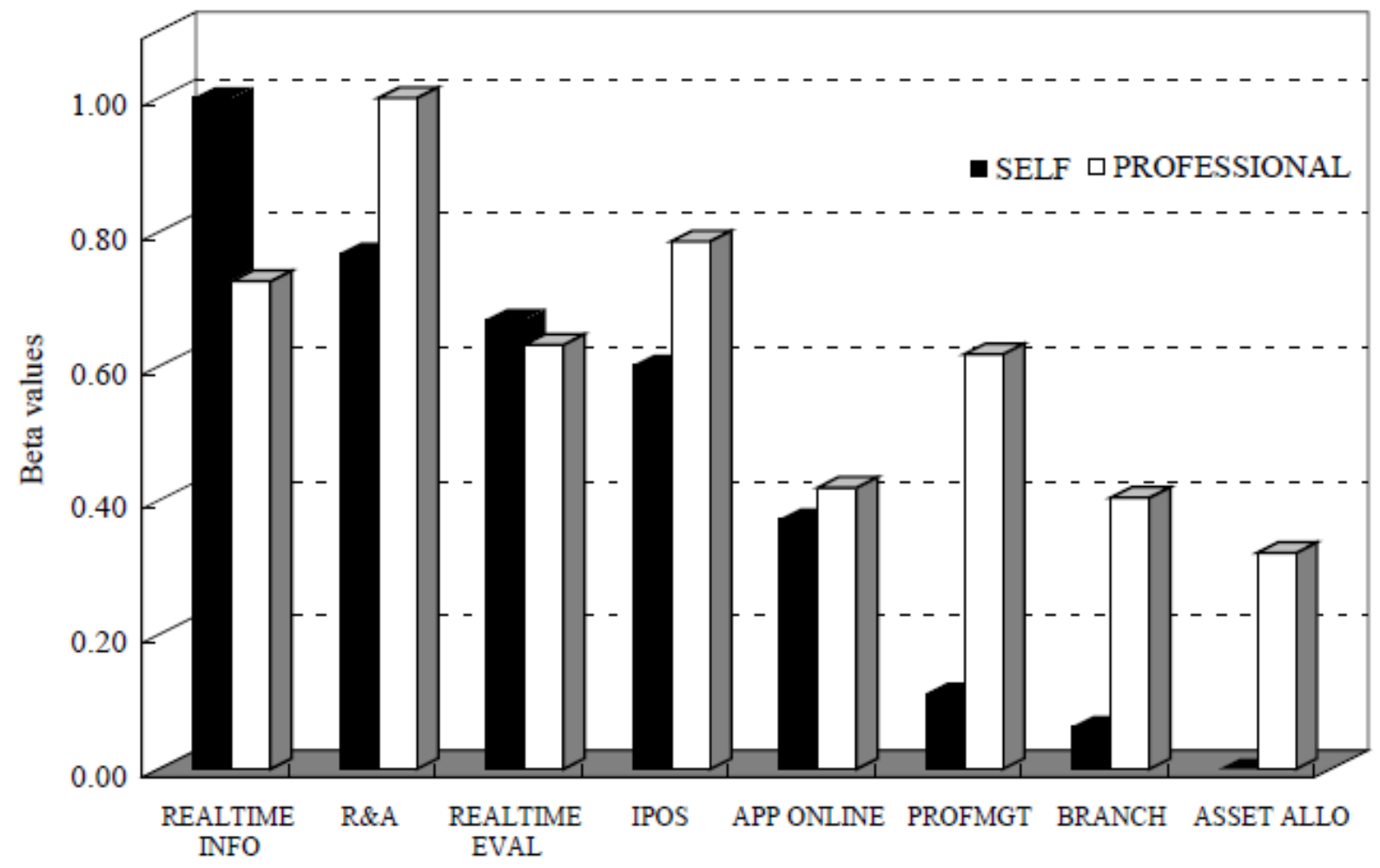

Figure 3. Comparison of two categories without price 


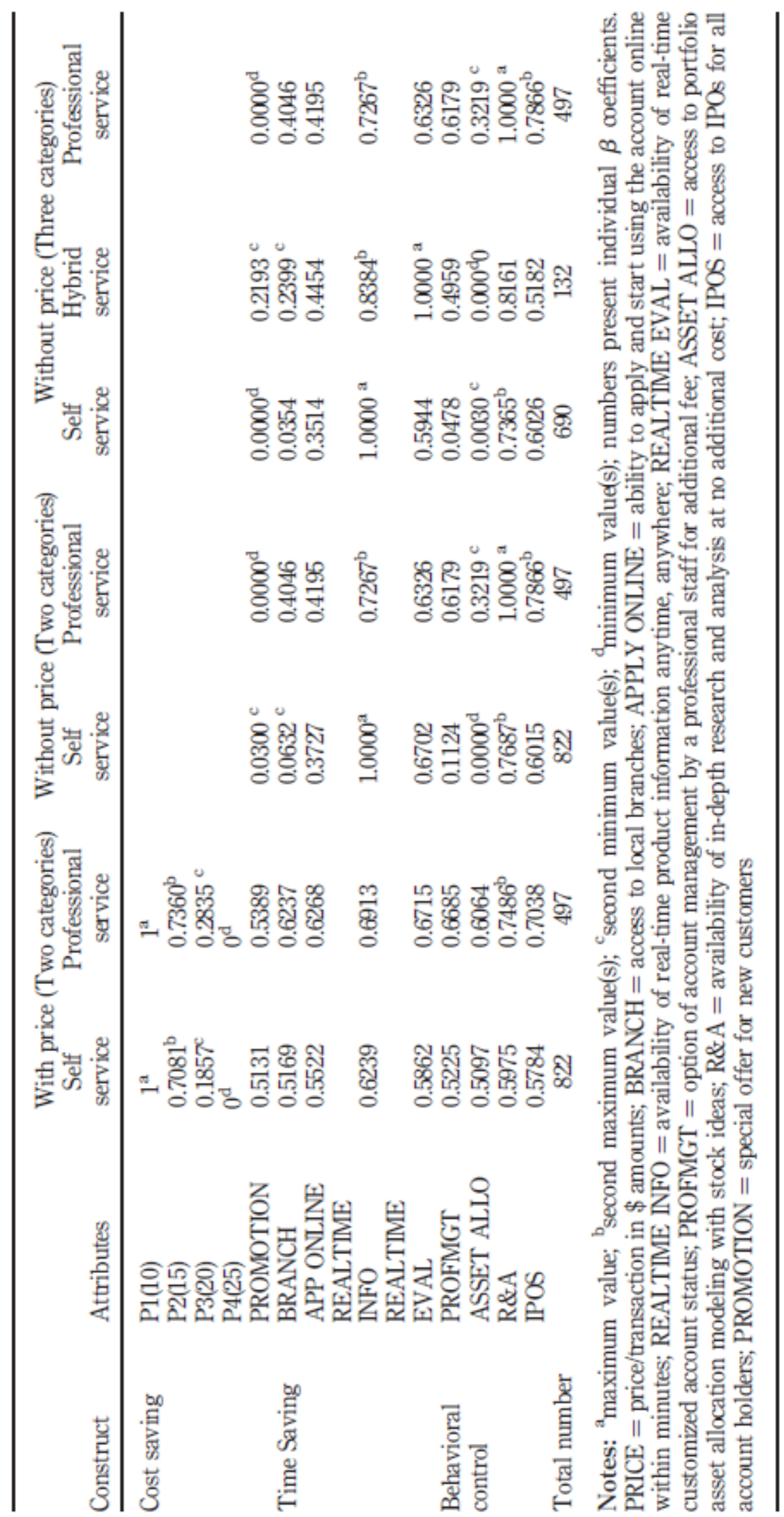

Table V.

Estimated $\beta$ values based on DCA for various customer segments 
4.1.2 Professional service consumers. It is interesting to note that besides price sensitivity, self-service users and professional service consumers are also least interested in promotion related special offers. One reasonable explanation for this finding is that both segments are risk averse and therefore not willing to risk sacrificing their portfolio performance by taking occasional special offers.

Besides the commonality between self-service consumers and professional service consumers, our results revealed professional service consumers place most value on the availability of in-depth research and analysis at no additional cost (R\&A). It is followed by access to IPOs (IPOS), real time information (REALTIME INFO), real time evaluation (REALTIME EVAL) and the fee-based professional managed accounts (PROFMGT) (R\&A = 1, IPOS = 0.7866, REALTIME INFO = 0.7267, REALTIME EVAL $=0.6326$, PROFMGT $=0.6179$ ). Meanwhile, professional service consumers rated the following factors with relatively lower coefficients: use the account online within minutes (APP ONLINE), local branch (BRANCH), asset allocation modeling with stock ideas (ASSET ALLO), and special offer (PROMOTION) (APP ONLINE = 0.4196, BRANCH $=0.4046$, ASSET ALLO = 0.3219, PROMOTION $=0$ ).

As a summary, although professional service consumers intend to rely on professional advisors in investment, they are still interested in understanding the advisors' recommendation by tracking related information in the way slightly different from that of self-service consumers. Generally, they will conduct more research and analysis $(R \& A=1)$ and tend to put more weight on the professional managed accounts (PROFMGT $=0.6179$ ). We may interpret this as a reflection of their lack of knowledge in financial investments compared with self-service consumers. Furthermore, for their unfamiliarity with the field, they are more risk averse to special offers (PROMOTION $=0$ ).

4.1.3 Hybrid-service customers. Intending to manage investments by themselves, hybridservice customers also like to check their plans with friends or family. The analysis demonstrates that the weights assigned to the nine independent variables in the hybrid segment are either mixes or aggregates of those in self-service and professional service segments (Figure 4). In general, hybrid-service customers evaluate the availability of streaming quotes and streaming news (REALTIME INFO), access to overall-fee-based and professionally managed accounts with a pre-determined investing strategy (PROFMGT), access to proprietary research at no additional cost (R\&A), and access to local branches (BRANCH) as the averages of corresponding weights for self-service and professional service segments (REALTIME INFO = 0.8384, PROFMGT $=0.4959, \mathrm{R} \& \mathrm{~A}=0.8161, \mathrm{BRANCH}=0.2399)$.

Interestingly, we found two tendencies worth noting for hybrid-service customers. First of all, they tend to put comparably extra emphases on the availability of real-time profit and loss portfolio evaluation, ability of apply online and be trading in minutes, special offers as compared to the other two segments of self-service and professional service (REALTIME EVAL = 1, APP ONLINE $=0.4454$, PROMOTION = 0.2193). Secondly, hybrid-service customers put slightly 
lower weights on access to IPOs for all account holders and access to portfolio asset allocation modeling with stock ideas (IPOs $=0.5182$, ASSET ALLO $=0$ ).

\section{$\underline{\text { Logistic Regression Analysis }}$}

The second objective of this study is to distinguish customer' choice of service approaches based on their demographic features. An overview of previous research in selfservice revealed the choice of service approaches relates to age, gender, education level, as well as familiarity with the technology and occupation. We define the dependent variable in the analysis as the service alternatives, which include self-service, hybrid service, and professional service. The independent variables are demographic characteristics, which include age, gender, education, occupation, and usage of the internet. Since, both the independent and dependent variables follow categorical distribution, we are applying multinomial logistic analysis to the model.

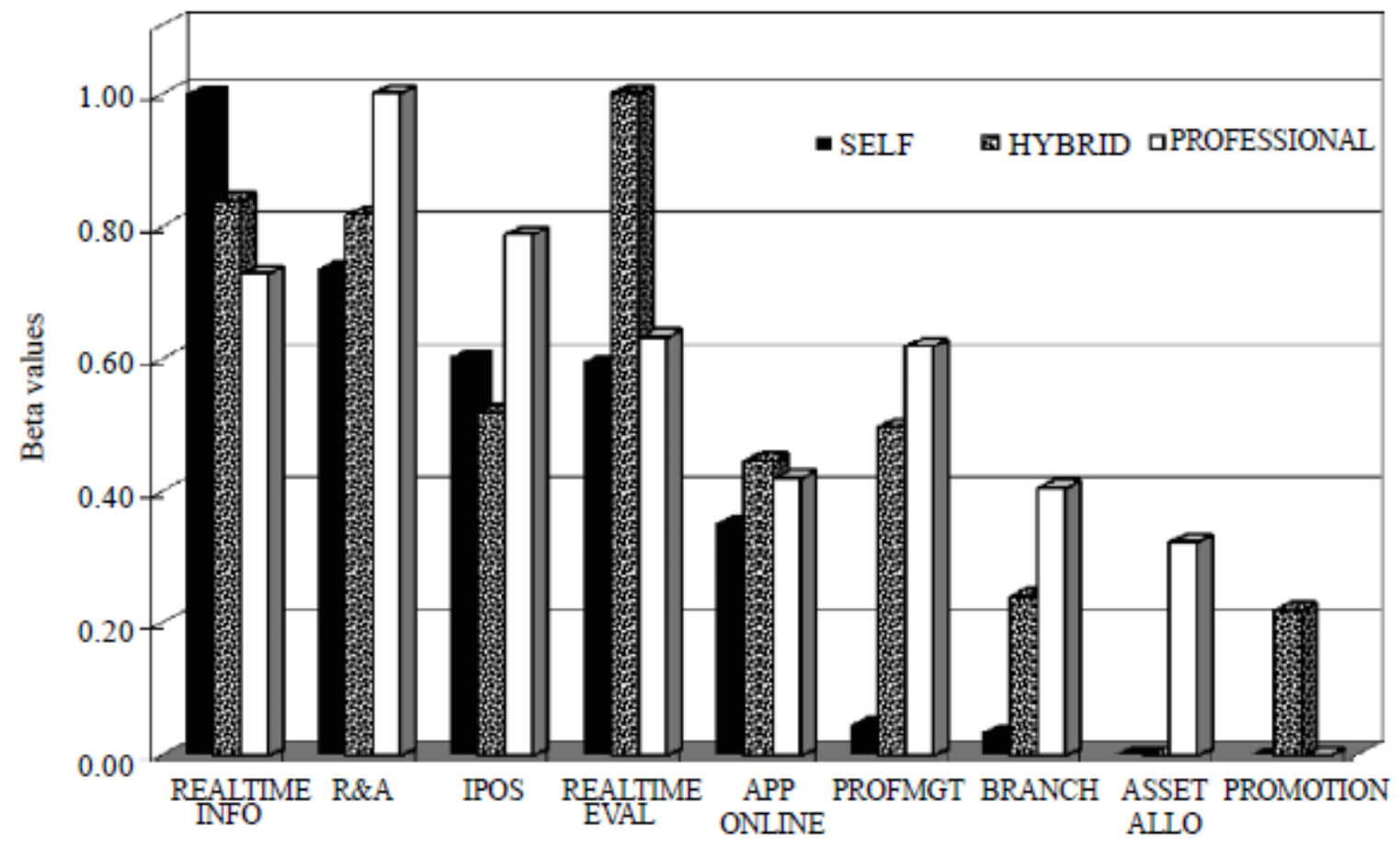

Figure 4. Comparison of three categories without price

Table VI presents summarized statistical information about the multinomial logistic regression model conducted with the five independent variables. As Table VI indicates, the model is significant with $\chi^{2}$ of 121.971 ( $P<0.001$ ). We checked the goodness-of-fit of the models using the likelihood ratio $\chi^{2}$ statistics. That is, we tested the hypothesis of $H_{0}: B_{1 i}=0$, versus $H_{0}: B_{1 i} \neq 0$, for $\forall i$. In the likelihood ratio tests, we found that overall, the three variables of age $(x 21 / 442.112, P, 0.001)$, access history $\left(\chi^{2}=17.287, \mathrm{P}<0.001\right)$ and gender $\left(\chi^{2}\right.$ $=16.060, \mathrm{P}<0.01)$ are identified with significant effect on the dependent variable of service alternatives. In contrast, the occupation $\left(\chi^{2}=11.594, p<0.5\right)$ and the education level of 
subjects $\left(\chi^{2}=9.915, \mathrm{P}<0.5\right)$ were not significant in differentiating the responses of the subjects to service alternatives. Therefore, they are dropped from further consideration.

Across all three segments of self-service, hybrid service and professional service customers, we found the age category for self-service segment approximates a normal distribution, with most service users at their early thirties to late forties. As a comparison, the largest portion of professional service customers were in their 40s-50s, while most of the hybrid users were in their 20s-30s. Following the exploration research in previous section, we can relate the difference in age distribution across customer segments to their experience and familiarity with online financial services, as well as their inherent resistance to new technology. We can find a reasonable explanation in the study by Howard and Worboys (2003): younger people tend to be more attitudinally enthusiastic about self-service options and think they are better qualified to use self-service routes than consultants. Meanwhile, older people are more confident as customers and will be better able to self-serve in certain applications (R\&A). However, they are less likely to be using the internet on a regular basis.

Our analysis also indicates the majority of three segments have access to internet for more than three years. Among which, 60.58 percent of the users in self-service segment have access to internet for more than five years. From both graphs, we can conclude the majority of self-service segment choose self-service as they are experienced on internet and they have an open mind towards new technology in online services. Although 74.65 percent of professional service segment do have above three years internet experience, they are reluctant to new technology such as online services and intend to adhere to traditional professional service.

\begin{tabular}{lcccc}
\hline Model & $-2 \log$ likelihood & $\chi^{2}$ & df & Significance \\
\hline $\begin{array}{l}\text { Final } \\
\text { Effect }\end{array}$ & 815.542 & 121.971 & 32 & 0.000 \\
AGE & $-2 \log$ likelihood of reduced model & & & \\
ACCESS HISTORY & 857.654 & 42.112 & 8 & 0.000 \\
GENDER & 832.830 & 17.287 & 6 & 0.008 \\
OCCUPATION & 831.602 & 16.060 & 2 & 0.000 \\
EDUCATION & 827.137 & 11.594 & 8 & 0.170 \\
Notes: The $\chi^{2}$ statistic is the difference in -2 log-likelihoods between the final model and a reduced \\
model. The reduced model is formed by omitting an effect from the final model. The null hypothesis is \\
that all parameters of that effect are 0
\end{tabular}

Table VI. Model fitting and likelihood ratio tests

As identified by previous research, the resistance to new technology is positively correlated with age. From which, we may interpret users' choice of self-service and professional service alternative as more related to the difference in age distribution rather than internet access. Finally, although 50.76 percent of hybrid service segment have more than five years internet experience, they choose to use both self-service and professional service in online financial services. Since, the majority of this segment is between 20s and 30s, we may interpret their 
choice as their relative lack of experience in financial investment, which outperforms their experience on internet.

Following prior research, this study also identifies females as more risk-averse than males and consequently consists only 32.17 percent of self-service segment. In contrast, there is an approximately equal opportunity for both male and female to appear in the remaining two segments. In general, 48.48 percent of hybrid service segment and 45.88 percent of professional service segment are comprised of females.

\section{Discussion and Managerial Implications}

Our study explores the drivers for various segments in online services. Broadly speaking, the results support prior self-services literature, which means self-service customers, in both an online context as well as with a high-involvement service, prefer personal control, time and cost saving, as well as the avoidance of personal contact in service. To restate the results within the context of online financial services, self-service users prefer real time information and evaluation, as well as free research and analysis tools. They try to avoid fee-based professional managed account and branches. For professional service users, they put most weight on free research and analysis tools and professionally managed accounts. In addition, they value least promotions and access to portfolio asset allocation modeling with stock ideas. The hybrid service segment is a mixture of the above two segments. Besides, users belonging to this segment stress the availability of real-time profit and loss portfolio evaluation, and the ability to apply online and be trading in minutes.

In addition to the differences, our results also indicate a few commonalities across the three segments. Firstly, users are sensitive to price per transaction, although self-service customers are more price sensitive than professional service customers. Secondly, users prefer to have free research and analysis tools and the ability to apply online and be trading in minutes. For self-service customers, they rely on real-time information and evaluation, as well as other free research and analysis tools to come up with their own investment portfolio. The study shows professional service customers are reluctant to use SST. However, because the majority of professional service customers are familiar with resources online (have access to internet for at least three years), they intend to make use of free research and analysis tools to interpret professional recommendation and make their own prediction.

Real-time information and availability of research and analysis are rated as the top two variables for self-service consumers, suggesting that these consumers value both timeliness of information and the quality of information. These results confirm earlier findings that the online medium not only provides timely information but also depth and breadth of information (Lynch and Ariely, 1999; Shapiro and Varian, 1999). Online consumers value this access to highquality information even more than other online-only features, further highlighting the power of the online medium in providing rich information. 
As these results indicate, even for high involvement, credence services in an online context, the existing literature on SST is highly predictive of behavior. Our study adds to that literature by demonstrating that in the context of high-involvement, credence services in an online context, cost savings in the form of price per transaction is paramount in choosing the service, irrespective of modality. One explanation for this deviation from existing literature is the context of our study, i.e. online services. Some researchers have demonstrated that the online medium tends to favor price-based competition (Lynch and Ariely, 1999; Iqbal et al., 2003). Thus, for providers of financial services, even to professional service users, cost saving is clearly the most important factor driving choice of service. As regards time saving and behavioral control, our results also add to past findings. Self-service users value time savings more than behavioral control whereas professional service users value behavioral control more than time savings. Thus, it appears that in the context of online, high-involvement credence services, self-service users prioritize attributes differently than professional service users; cost savings, time savings and behavioral control for self-service users; and cost savings, behavioral control and time savings for professional service users. Thus, depending on the type of segment targeted, managers are well served by using our findings to create the appropriate mix of attributes for the appropriate segment. More importantly, managers can use our results to create the right message to communicate their service to the appropriate segment.

Finally, our results demonstrate that the mix of attributes used in most financial services seems to be the right mix; what needs to change is the prioritization and emphasis on the appropriate subset of attributes depending on the segment targeted. Managers are ill-served by using a "one-size-fits-all" approach and our results provide valuable direction with respect to accurate targeting.

To demonstrate the application of the above findings in a real-life scenario, we incorporated the $b$ values calculated from the previous MNL model into an Excel spreadsheet. Managers can use this simple model to evaluate the expected changes in market share by altering one or more attributes. The application is illustrated in the following example, depicted in Table VII. Assuming that there are only three companies (hypothetical companies) offering online financial services, Morgan Standard Co. (MSC), US Mutual (USM), Western Investment Online (WIO), in the geographical region from which the data was collected. The attributes for the three companies and their corresponding design codes are as follows (listed in Table VII): MSC provides streaming quotes and streaming news, as well as access to IPOs for all account holders. Both USM and WIO provides fee-based professionally managed account, access to local branches. Besides, USM offers real-time profit and portfolio evaluation and promotions, and WIO offers additional service of proprietary research at no additional cost, access to IPOs for all account holders, portfolio asset allocation modeling with stock ideas.

Table VII also shows that the design codes for attributes can be multiplied by their respective $\beta$ values calculated from the MNL model to estimate the overall utility for each company per customer segment. The expected market share for each company can also be 


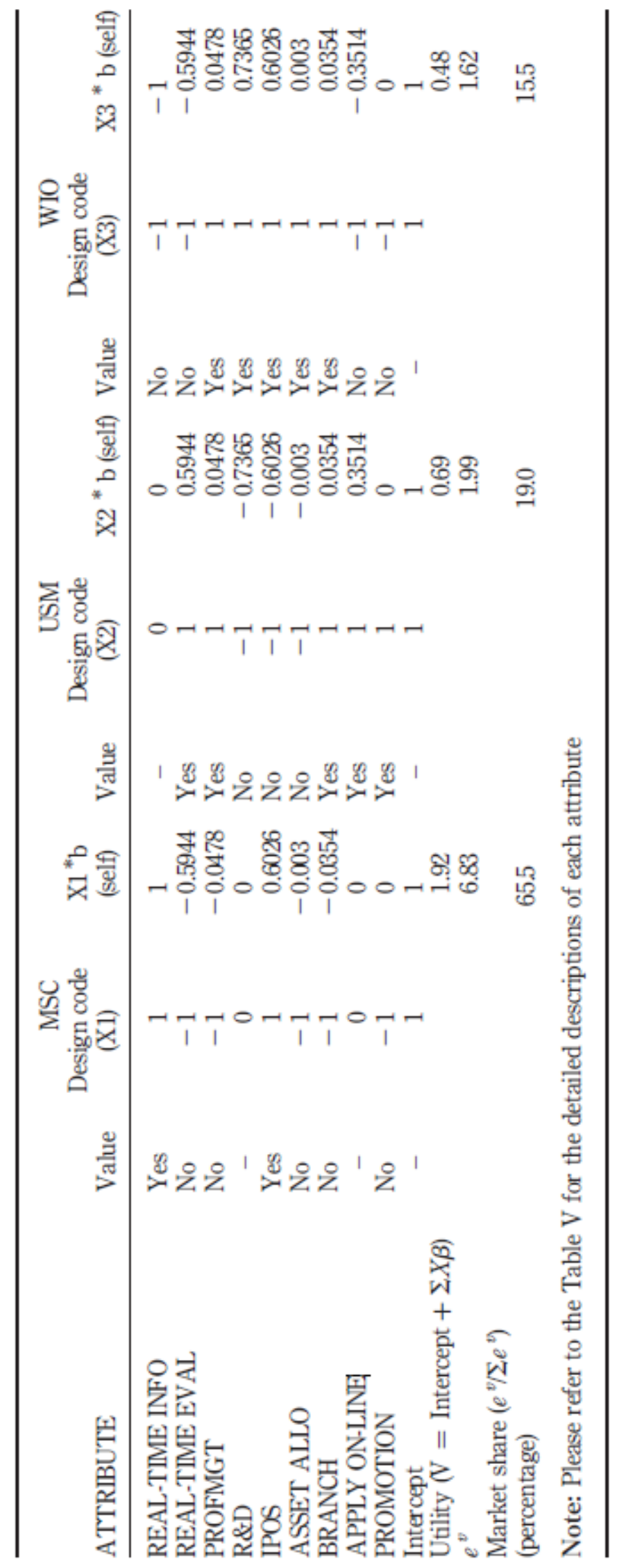

Table VII. Sample managerial application of customer choice models 
calculated by using the MNL shown in Table VII. In general, the expected market shares with the attribute levels shown are: self-service segment (MSC: 65.5 percent, USM: 19.0 percent, WIO: 15.5 percent), hybrid service segment (MSC: 13.4 percent, USM: 70.8 percent, WIO 15.8 percent), professional service segment (MSC: 11.5 percent, USM: 17.7 percent, WIO: 70.8 percent). The $\beta$ values calculated from the MNL model (Table $\mathrm{V}$ ) can be easily applied to estimate market share for companies offering various combinations of attributes.

\section{Importance of Demographic Variables}

We also find the demographic characteristics relate to customers' choice of service channels. In general, older customers at their late 40s and 50s are more inclined to use traditional professional services while using the online service as a quick approach for obtaining timely information and conducting research. In comparison, customer in 30s and 40s are more likely to choose self-service for time and cost savings. Customers in their 20 s and early 30 s appear to be more likely to use both online self-service and offline professional service. Besides age, gender also has a close relationship with customers' choice of service channels. Females tend to be more risk averse by refusing to use self-service as the major channel in online services. Therefore, they only comprise one third of self-service segment. Besides age and gender, history of accessing to internet does not explain much of the variance across segments. Education level and occupation do not contribute to the difference among three segments in any way.

Based on the overall findings, we can conclude that although commonalities exist across different customer segments, each segment assigns different weights to various features. The sample multinomial-logit model in Table VII demonstrates that various combination of service options leads to different market shares across customer segments. Besides, the preferences towards service alternatives could be partially explained by customer demographic characteristics. Based on these conclusions, we will recommend to managers that they provide customized service based on the demographic features of each user. As suggested by previous research, effective customization will result in improved perceived ease of use and time saving, and consequently lead to increased satisfaction levels and intention to repeat purchase. Service designers could re-arrange the layout of customized pages based on age and gender, as well as usage of internet of each customer. For example, we can infer that infrequent female users in their forties most probably belong to professional service segments instead of being either selfservice or hybrid service customers. Therefore, it will be more feasible to customize web pages for them by highlighting research and analysis links, related information on fee based professional managed account, as well as real time streaming quotes and streaming news. For frequent male users in their forties, it is likely that they are self-service users. Therefore, the customized web pages should highlight real time streaming quotes and streaming news, research and analysis tools, access to IPOs links, as well as tools for real-time profit and loss portfolio evaluation. 
Overall, our study extends the existing literature on SST into the online context and to high-involvement credence services. Our study also enables practicing managers to accurately segment users based on their mode of service usage and to target them with the right prioritization of features. Finally, our study highlights the differing importance of frequently used demographic variables in creating segments, the most relevant ones being age, internet access history and gender. Thus, our study serves to both enhance the existing SST literature as well as to provide valuable insights for managers competing in an online context with highinvolvement credence services.

\section{Limitations and Future Research Directions}

Although our study contributes to the self-service literature by introducing online financial services into the domain, it has some limitations. First, we only studied the online financial industry and hence our study has limited generalizability. At the very beginning of the paper, we argue that the findings should be applicable to other online services. However, the set of motivations for choosing self-service should be examined in other industries. Examples of such research could be travel industry (Shankar et al., 1999), and the grocery industry (Degeratu et al., 2000). Second, our study only collects the transaction amount in previous year. In general, the transaction amount alone cannot explain the choice of service. For example, users who are specialized in the stock markets will go through the transaction very frequently. Consequently, they are more inclined to automate the transaction process by using self-service online. However, the transaction amount alone cannot capture this factor. Third, the criteria used to segment customers are not perfect. Future studies can use more detailed and accurate criteria such as latent class and other segmentation techniques to allow segments to emerge from the data, thus accounting for heterogeneity that may exist between segments (Degeratu et al., 2000). Fourth, future studies can also use a continuous variable to present preferences towards both online self-service and offline professional service. In that way, we can better interpret the problem on a continuous basis instead of discrete way. Besides, it may be interesting to conduct a longitudinal research to study the variation of customer preferences towards different service alternatives, as well the impact of promotion and loyalty related issues. It is also interesting to see whether other demographic features such as investment experience and income level will affect customers' choice of service channels. Building upon the studies by Bendapudi and Leone (2003), future research should also study whether re-designing online service process based on the $b$ values estimated from the MNL model will increase service quality and customer satisfaction. Although there are multiple directions for future research on the basis of this study, we believe our results and conclusions contribute to existent literature on self-service and also enable managers to create customized online services that better satisfy different customer segments.

\section{References}

Bateson, J.E.G. (1985), "Self-service consumer: an exploratory study", Journal of Retailing, Vol. 61 No. 3, pp. 49-76. 
Bendapudi, N. and Leone, R.P. (2003), "Psychological implications of customer participation in co-production", Journal of Marketing, Vol. 67 No. 1, pp. 14-28.

Berry, L., Seiders, K. and Grewal, D. (2002), “Understanding service convenience”, Journal of Marketing, Vol. 66 No. 3, pp. 1-17.

Bitner, M.J., Booms, B.H. and Mohr, L.A. (1994), “Critical service encounters: the employee's view", Journal of Marketing, Vol. 58 No. 4, pp. 95-106.

Boyes, G. and Stone, M. (2003), "E-business opportunities in financial services", Journal of Financial Services Marketing, Vol. 8 No. 2, pp. 176-89.

Brush, T.H. and Artz, K.W. (1999), "Toward a contingent resource-based theory: the impact of information asymmetry on the value of capabilities in veterinary medicine", Strategic Management Journal, Vol. 20 No. 3, pp. 223-50.

Cook, D., Goh, C. and Chung, C. (1999), "Service typologies: a state of the art survey", Production and Operations Management, Vol. 8 No. 3, pp. 318-38.

Dabholkar, P.A. (1996), “Consumer evaluations in new technology-based self-service options: an investigation of alternative models of service quality", International Journal of Research in Marketing, Vol. 13 No. 1, pp. 29-51.

Dabholkar, P.A. and Bagozzi, R.P. (2002), “An attitudinal model of technology-based selfservice: moderating effects of consumer traits and situational factors", Academy of Marketing Science Journal, Vol. 30 No. 3, pp. 184-201.

Danaher, P.J. (1997), "Using conjoint analysis to determine the relative importance of service attributes measured in customer satisfaction surveys", Journal of Retailing, Vol. 73 No. 2, pp. 235-60.

Degeratu, A.M., Rangaswamy, A. and Wu, J. (2000), "Consumer choice behavior in online and traditional supermarkets: the effects of brand name, price, and other search attributes", International Journal of Research in Marketing, Vol. 17 No. 1, pp. 55-78.

Globerson, S. and Maggard, M.J. (1991), “A conceptual model of self-service”, International Journal of Operations \& Production Management, Vol. 11 No. 4, pp. 33-43.

Green, P.E. and Krieger, A.M. (1996), "Individualized hybrid models for conjoint analysis", Management Science, Vol. 42 No. 6, pp. 850-67.

Holmlund, M. (2001), "The D\&D model-dimensions and domains of relationship quality perceptions", The Service Industries Journal, Vol. 21 No. 3, pp. 13-36.

Howard, M. and Worboys, C. (2003), "Self-service - a contradiction in terms or customer-led choice?", Journal of Consumer Behavior, Vol. 2 No. 4, pp. 382-92. 
Iqbal, Z., Verma, R. and Baran, R. (2003), "Understanding consumer choices and preferences in transaction-based e-services", Journal of Service Research, Vol. 6 No. 1, pp. 51-65.

Kelley, S.W., Donnelly, J.H., James, H. and Skinner, S.J. (1990), “Customer participation in service production and delivery", Journal of Retailing, Vol. 66 No. 3, pp. 315-35.

Langeard, E., Bateson, J., Lovelock, C. and Eigilier, P. (1981), "Services marketing: new insights from consumer and managers", Report No. 81-104, Marketing Science Institute, Cambridge, MA.

Lee, J. and Allaway, A. (2002), "Effects of personal control on adoption of self-service technology innovation", The Journal of Service Marketing, Vol. 16 No. 6, pp. 553-72.

Lohse, G.L., Bellman, S. and Johnson, E.J. (2000), "Consumer buying behavior on the internet: findings from panel data", Journal of Interactive Marketing, Vol. 14 No. 1, pp. 15-29.

Louviere, J.J. (1988), Analyzing DecisionMaking: Metric ConjointAnalysis, Sage, Newbury Park, CA.

Louviere, J.J. and Timmermans, H. (1990), "Stated preference and choice models applied to recreation research: a review", Leisure Science, Vol. 12, pp. 9-32.

Lovelock, C.H. (2001), Services Marketing: People, Technology, Strategy, Prentice-Hall, Englewood Cliffs, NJ.

Lynch, J.G. and Ariely, D. (1999), "Electronic shopping for wine: how search costs affect consumer price sensitivity, satisfaction with merchandise, and retention", Working paper, Report No. 99-104, Marketing Science Institute, Cambridge, MA.

Mentzer, J.T., Flint, D.J. and Hult, G.T.M. (2001), "Logistics service quality as a segmentcustomized process", Journal of Marketing, Vol. 65 No. 4, pp. 82-104.

Meuter, M.L. and Bitner, M.L. (1998), "Self-service technologies: extending service frameworks and identifying issues for research", AMA Winter Educator's Conference Proceedings: Marketing Theory and Applications, Vol. 9, pp. 12-19.

Meuter, M.L., Ostrom, A.L., Roundtree, R.I. and Bitner, M.J. (2000), "Self-service technologies: understanding customer satisfaction with technology-based service encounters", Journal of Marketing, Vol. 64 No. 3, pp. 50-64.

Ostrom, A. and lacobucci, D. (1995), "Consumer trade-offs and the evaluation of services", Journal of Marketing, Vol. 59 No. 1, pp. 17-28.

Parasuraman, A. (1996), "Understanding and leveraging the role of customer service in external, interactive and internal marketing", paper presented at Frontiers in Services Conference, Nashville, TN, October. 
Sarel, D. and Marmorstein, H. (2003), "Marketing online banking services: the voice of the customer", Journal of Financial Services Marketing, Vol. 8 No. 2, pp. 106-18.

Shankar, V., Rangaswamy, A. and Pusateri, M. (1999), "The impact of internet marketing on price sensitivity", working paper, Penn State e-Business Research Center, State College, PA.

Shapiro, C. and Varian, R. (1999), Information Rules: A Strategic Guide to the Network Economy, Harvard Business School Press, Boston, MA.

Taylor, S. and Todd, P. (1995), "Understanding information technology usage: a test of competing models", Information Systems Research, Vol. 6 No. 2, pp. 144-76.

Verma, R., Thompson, G.M., Moore, W.L. and Louviere, J.J. (2001), “Effective design of products/services: an approach based on integration of marketing and operations management decisions", Decision Science, Vol. 32 No. 1, pp. 165-93.

Yang, Z. and Jun, M. (2002), "Consumer perception of e-service quality: from internet purchaser and non-purchaser perspectives", Journal of Business Strategies, Vol. 19 No. 1, pp. 1941.

Zeithaml, V., Parasuraman, A. and Malhotra, A. (2000), "A conceptual framework for understanding e-service quality: implications for future research and managerial practice", working paper series, Marketing Science Institute, Cambridge, MA.

\section{Further Reading}

Anderson, N. (1971), "Integration theory and attitude change", Journal of Personality and Social Psychology, Vol. 18 No. 2, pp. 230-3.

Bettman, J., Capon, N. and Lutz, R. (1975), "Cognitive algebra in multi-attribute models", Journal of Marketing Research, Vol. 12 No. 2, pp. 151-64.

Bishop, Y., Frenberg, S. and Holland, P. (1978), Discrete Multivariate Analysis - Theory and Practice, The MIT Press, Cambridge, MA.

Dickson, P.R. and Ginter, J.L. (1987), “Market segmentation, product differentiation, and marketing strategy", Journal of Marketing, Vol. 51 No. 2, pp. 1-10.

Lancaster, K. (1975), Variety, Equity, and Efficiency, Columbia University Press, New York, NY.

Mentzer, J.T. (1993), "Managing channel relations in the 21st century", Journal of Business Logistics, Vol. 14 No. 1, pp. 27-42.

Rosen, S. (1974), "Hedonic prices and implicit markets: product differentiation in pure competition", Journal of Political Economy, Vol. 82 No. 1, pp. 34-55. 


\begin{abstract}
About the Authors
Xin Ding is an Assistant Professor of Organizational Leadership and Project Management at the University of Houston. He holds PhD degree in Operations Management from David Eccles School of Business, University of Utah. His research focuses on service operations, quality control, service quality, and e-commerce. His paper has appeared in the Decision Science Journal of Innovation Education. He is a member of the Decision Science Institute, Production and Operations Management Society, and Institute for Operations Research and the Management Sciences. Xin Ding is the corresponding author and can be contacted at: pmgtxd@business.utah.edu

Rohit Verma is an Associate Professor of Service Operations Management at the Cornell University, School of Hotel Administration. Prior to his current appointment, he was the George Eccles Professor of Management, David Eccles School of Business at the University of Utah. His research interests include product/service design, innovation and process improvement, supplier selection strategies, and operations/marketing interrelated issues. He has published over 40 articles in business journals such as California Management Review, Cornell Quarterly, Decision Sciences, Journal of Operations Management, Journal of Product Innovation Management, Journal of Service Research, MIT Sloan Management Review, Production and Operations Management, and other journals. He serves as the Associate Editor of Journal of Operations Management, and Decision Sciences; Senior Editor of Production and Operations Management; and Editorial Board Member of Journal of Service Research, and Cornell Hotel and Restaurant Administration Quarterly. E-mail: rv54@cornell.edu
\end{abstract}

Zafar Iqbal is Associate Professor of Marketing at DePaul University. His research focuses on the areas of new product and service development, managerial decision making, developing practical tools for marketers, and gray markets. He has published various articles in California Management Review, Journal of Service Research, Journal of Internet Commerce, Journal of Personal Selling and Sales Management and Journal of Risk and Insurance. E-mail: ziqbal@depaul.edu 